\title{
Chapter 4 \\ Transformative Value Co-creation in Healthcare Services in the COVID-19 \\ Era: The Case of Centro Cardiologico Monzino
}

\section{Roberta Sebastiani and Alessia Anzivino}

\begin{abstract}
The outbreak of COVID-19 has presented great challenges for health services targeted at patients with chronic diseases, such as cardiovascular disorders. Hospitals and medical clinics must find new and effective solutions to address the impacts on individual and collective well-being due to the increased diffusion of these types of diseases, especially during a pandemic. This implies the evolution of the service ecosystem through enhanced coordination and resource integration between different actors (patients, doctors, service providers, relatives, caregivers, etc.). The coordination process might be leveraged by technological devices aimed at integrating resources and co-creating transformative value (Anderson et al. 2013; Danaher and Gallan 2016; Anderson et al. 2018). This chapter, in particular, investigates how digital health technologies impact the evolution of the Italian healthcare service ecosystem in a transformative way through the study of the case of Centro Cardiologico Monzino. The study adopted a qualitative approach based on in-depth interviews with patients of Centro Cardiologico Monzino with cardiovascular pathologies who use digital health devices and doctors, caregivers, and other key informants who are experts in the Italian healthcare service ecosystem. Our findings illustrate how digital health contributes to value co-creation and to the enhancement of individual and collective well-being, considering the renewed interaction between different actors in the service ecosystem.
\end{abstract}

Keywords Transformative value co-creation - Service ecosystem • Digital health • Individual and collective well-being

\footnotetext{
R. Sebastiani · A. Anzivino ( $\square)$

Catholic University of the Sacred Heart, Milan, Italy

e-mail: Alessia.anzivino@unicatt.it

R. Sebastiani

e-mail: Roberta.sebastiani@unicatt.it
}

J. Lee and S. H. Han (eds.), The Future of Service Post-COVID-19 Pandemic, Volume 1,

The ICT and Evolution of Work,

https://doi.org/10.1007/978-981-33-4126-5_4 


\subsection{Introduction}

COVID-19 seems to have projected us all into that social and temporal dimension that anthropologists call "liminality" (Horvath et al. 2015). The pandemic has suspended all ordinary activities and identities. We no longer act from a project perspective but only in the contingency of the very short term. For example, in this period, attention has been focused on COVID-19 patients, while patients with other diffuse and chronic pathologies, such as cardiac disease and diabetes, were neglected. Instead, nonCOVID-19 patients seem to have disappeared from social communication, as if their illnesses were also suspended. Unfortunately, however, they are not, though in many cases clinics have been closed and appointments postponed. Even though activity in hospitals resumed, patients have been afraid of going there. This phenomenon has not only occurred in Italy but in the rest of the world.

According to a survey conducted between March and April 2020 by Carenity, a social platform that brings together more than 400,000 chronic patients and caregivers from around the world, and Alira Health (Carenity and Alira Health 2020), $42 \%$ of patients have had a consultation or surgery cancelled or rescheduled, $40 \%$ report consulting their doctor less often than usual, $9 \%$ have stopped and/or interrupted their background treatment, and $10 \%$ reported that they have had difficulty finding their prescription in a pharmacy. These figures show a substantial risk of therapeutic discontinuation for patients requiring regular care and treatment.

Among chronic diseases, cardiovascular diseases (CVDs) are the leading cause of death globally, according to World Health Organization (WHO) data (Health Organization 2020), claiming an estimated 17.9 million lives each year and accounting for approximately $31 \%$ of all deaths worldwide. CVDs are a group of disorders of the heart and blood vessels and include coronary heart disease, cerebrovascular disease, rheumatic heart disease, and other conditions. Four out of five CVD deaths occur in people under 70 years of age due to heart attacks and strokes. One-third of these deaths occur prematurely. In Italy, there are 240,000 victims of heart disease per year; cardiovascular diseases are responsible for $44 \%$ of all deaths, and those who survive a heart attack become chronic patients.

Imagine, for a moment, a typical chronic patient with a cardiovascular disease who needs to go to the hospital. Usually, the patient would call for an ambulance or otherwise go to the hospital, and after the usual triage, they would receive specific care.

But what happens during the COVID-19 era?

During the lockdown, the scenario in Italy changed because of the rapid reorganization of hospitals and the increased burden on the emergency system due to the pandemic. People with cardiovascular diseases preferred to stay home, even in severe cases. Based on the numbers of the first Italian multicenter study (De Rosa et al. 2020) conducted in 54 hospitals, the Italian Cardiology Society stated that during the COVID-19 emergency, mortality from heart attacks tripled and, in most cases, were linked to non-treatment or delayed treatment. About 7.5 million Italians suffer from cardiovascular diseases, and during this pandemic, a reduction of more 
than $50 \%$ in hospitalizations for heart attacks has been registered. Hospitalizations for heart failure, heart rhythm abnormalities, and dysfunction of pacemakers and defibrillators are down by about a third.

Given this scenario, it is necessary to re-consider the service ecosystem in healthcare and how digital health could represent, in this process, a long-term strategy for the healthcare system. Since the pandemic has boosted the use of digital technologies to address the need for social distancing, actors involved in the healthcare service ecosystem are moving toward transforming the crisis into a great moment of rethinking the organizational and relational models of care based on these types of technologies.

In the United States, during the COVID-19 pandemic, the majority of patient consultations are happening virtually, and healthcare planners are shifting toward systems of virtual care based on China's experiences where patients were advised to seek medical help online in order to avoid problems related to contagion in hospitals and delays in treatment (Webster 2020). As of 2018, in Italy, each of the 20 regions implemented national telemedicine according to specific guidelines, but we can say that it was only in its primary stage and involved very few patients (Infection Control Today 2020). The changes to the traditional structures and consequently to service ecosystems due to the use of digital technologies, were consolidated and strengthened, thus introducing new ways to integrate resources to co-create transformative value. In cardiology, remote monitoring of electronic cardiovascular devices, such as defibrillators and cardiac resynchronization systems implanted in patients with severe arrhythmias or heart failure, already existed, but during the COVID-19 pandemic, this was implemented in a more effective way. Information concerning both the state of the device and the patient's clinical condition moves periodically through a secure and protected system from the patient's home to computer platforms that are reviewed by cardiology technicians and cardiologists in the hospital (Lakkireddy et al. 2020).

Vargo and Lusch (2016) have defined the service ecosystem concept as "relatively self-contained, self-adjusting systems of resource-integrating actors connected by shared institutional arrangements and mutual value creation through service exchange" (p. 11). But which is the value in this particular case, that is, what is the object of the service ecosystem change? The purpose of the healthcare service system targeted to patients of chronic diseases, is to co-create a specific form of value, the transformative value, that encompasses the "social dimension of value creation which illuminates uplifting changes among individuals and collectives" (Blocker and Barrios 2015, p. 2).

This chapter investigates how digital health impacts the evolution of the Centro Cardiologico Monzino service ecosystem in a transformative way, in particular, during and after this pandemic, how transformative value is co-created, who the actors are, and how the resource integration mechanisms and logics are changing.

The study adopted a qualitative approach based on thirty two in-depth interviews: ten patients with cardiovascular pathologies using digital health devices useful for their own body and its vital functions, four caregivers, seven clinicians, two technology providers, six nurses, and three experts in the Italian healthcare service 
ecosystem. The data were triangulated with those derived from participatory observation and from the analysis of secondary data. The data were collected in parallel, and the various sets of results were interpreted concurrently to draw valid conclusions regarding the research problem.

This chapter is structured as follows. The next section is dedicated to the research setting. Then the Centro Cardiologico Monzino service ecosystem is described and pillars of transformative value co-creation are discussed. We end with conclusions and managerial implications.

\subsection{Research Setting: Centro Cardiologico Monzino}

Centro Cardiologico Monzino was established in 1981, and it was the first hospital in Europe exclusively dedicated to the treatment of cardiovascular diseases. Today, the center is part of IEO-Monzino group, which includes two centers of excellence in the management of the major pathologies of the Western world that reinvest all their profits in research and innovation. Monzino is accredited and affiliated with the Lombardy Region and offers admissions and outpatient services under the National Health Service. In 1992, it became the first clinical research hospital in Italy dedicated exclusively to cardiovascular diseases. As a research hospital, Monzino pursues research, mainly clinical and translational, in the biomedical field as well as in the organization and management of health services, together with admissions and highly specialized treatment of cardiovascular diseases. The activities of Monzino are inspired by values such of specialization, research, interdisciplinary care, and continuity of services aimed at keeping the individual at the center of attention.

Centro Cardiologico Monzino was set up as the main seat of the Università Statale of Milan for the study of Cardiovascular disease: thus, it contributes to training, producing clinical excellence in all specific roles, in order to offer the best care.

At Monzino, scientists, physicians, technicians and nurses work together sharing highly specialised individual knowledge, to provide the best patient care and to establish a trusting relationship in a collaborative and confidential environment. This approach to work is our key to carrying out innovative research, prevention and care projects.

The Monzino Centre is a patient-oriented institute that accompanies patients throughout the course of their therapy.

A total of 12 Research Units, with 75 researchers are active at Centro Cardiologico Monzino, that led to 212 publications in scientific magazines (1.423 Impact Factor in 2016) with an excellent scientific productivity rate per researcher, directly integrated with hospital areas to transform results achieved into new approaches for prevention, diagnosis and patient care as quickly as possible.

Constantly improving knowledge of the heart's "language" and that of its cells, the centre's laboratories search for new markers that would allow better prevention of cardiovascular disease and prompter, more personalized and effective care. 
A further field of research concerns the use of innovative equipment for diagnostic and surgery procedure imaging, to make the detection and treatment, for instance, of coronary disease, more effective and less invasive.

A few years ago, Monzino Digital was born; like all centers of excellence, the Monzino Cardiology Center had already integrated a large amount of cutting-edge digital technologies for its clinical-scientific activity, for example, the most advanced cardiovascular imaging equipment or research equipment. But it is to the strengthening of center relationship with the patient and the citizen that the "Digital" is contributing in an unexpected and very rapid way during this COVID-19 period.

During the COVID-19 period, digital health technologies have played a leading role and is expected to play a more important role in the future management of heart disease and especially, in reducing cardiovascular risk after the pandemic. In fact, the European Society of Cardiology (ESC) has launched its own commission, the "Digital Health and Cardiology Commission."

\subsection{Service Ecosystems and Transformative Value Co-creation in Centro Cardiologico Monzino}

The value creation process, as depicted in service-dominant logic (Vargo and Lusch 2011, 2016), is an interactive and collaborative process occurring in the context of a unique set of multiple exchange relationships among various actors in a service ecosystem.

Service ecosystems represent spatial and temporal structures of loosely coupled, value-proposing social and economic actors engaging in mutual service provision and value co-creation (Vargo et al. 2015). They reconfigure themselves when necessary; they are dynamic and potentially self-adjusting. Service provision and value creation through resource integration impact the nature of the system. These dynamics, in turn, determine a change in the context for future value creation processes (Chandler and Vargo 2011). Resource integration, service provision, and value creation change the system's nature to some degree and, thus, the context for the next interaction and determination of value creation.

Multiple levels of sub-ecosystems that intersect and overlap at the micro, meso, and macro levels of social interaction compose service ecosystems (Alexander et al. 2018). The macro-level structure is derived from interactions at the meso level, which in turn, is determined by interactions at the micro level (Lusch and Vargo 2014). Consequently, the macro-level system exerts an influence on the lower levels - that is, meso and micro-over time, varying according to the context (Alexander et al. 2018). At each level, actors interact with co-creating value and shaping the social context. Thus, value co-creation in service ecosystems is a complex process involving the integration of resources from numerous sources in unique ways, which in turn, provide the possibility of new types of service provision that require coordination. 
The extant literature focuses primarily on how value co-creation occurs at a micro level, within the dyad, while the mechanisms that govern value co-creation at the different levels of a service ecosystem are much less investigated. Scholars increasingly recognize the importance of the social and collective dimensions of value creation that influence well-being both at the individual and at the societal level. This effort gave rise to a specific research stream called "Transformative Service Research" (TSR) (Anderson et al. 2013; Anderson and Ostrom 2015) that "centres on creating uplifting changes and improvements in the well-being of individuals (consumers and employees), communities, and ecosystems" (Anderson et al. 2013, p. 1). Individual well-being refers to the "reflective cognitive evaluations of life" and "affective reactions to life events" that happen to an individuals" "bodies and minds, and the circumstances in which they live" (Diener 2006, p. 153). Collective wellbeing refers to a positive state of affairs in which the collective needs and aspirations of individuals and communities are fulfilled (Evans and Prilleltensky 2007).

Individual as well as collective well-being represent the forms of transformative value that encompass the "social dimension of value creation which illuminates uplifting changes among individuals and collectives" (Blocker and Barrios 2015, p. 2) within service ecosystems.

To explore the co-creation of transformative value in health services, TSR suggests a contextual analysis that detaches itself from the more traditional analyses of loyalty and consumer satisfaction; the aim is to investigate the effects that services can have in terms of uplifting individual and collective well-being based on the assumption that healthcare organizations focus their activities on improving patients' lives.

In the current epidemic context, a digitally mediated healthcare service ecosystem emerges as a disruptive reality useful to provide new solutions and manage new links and actors' and resources' integration to co-create transformative value.

Until now, digital technologies have been used as an alternative method of interacting with patients in the healthcare sector, and these innovative technologies have been useful in improving education, preventative care, and the relationship between patients and health professionals with regard to treating cardiovascular diseases.

Even if the use of technologies in the healthcare industry faces challenges, such as the lack of financial resources (Saborowski and Kollak 2015), during this pandemic, the systematic availability of health-related information, gathered by wearables, sensors, and smartphone technologies has further enhanced patient performance in co-creating transformative value with the provider and for themselves (Aceto et al. 2018; Osei-Frimpong et al. 2018).

The intervention of technological advancements in a service ecosystem defines a new systemic network and the development of new social practices, such as continuous remote monitoring of patients' symptoms, sharing clinical data, and patient empowerment (Caridà et al. 2014; Osei-Frimpong et al. 2018).

Using data derived from our interviews, we found three different macro themes at the base of the recent evolution of the Centro Cardiologico Monzino service ecosystem in a transformative way thanks to digital technologies: 
- newfangled actors engagement,

- digitally mediated resource integration,

- newly emerging barriers and tensions.

\subsubsection{Newfangled Actors Engagement}

The improvement of the use of digital technologies in healthcare systems and the reshaping of the Centro Cardiologico Monzino service ecosystem is connected to a novel way of actor engagement. At the micro level, the correct management of digital devices by patients with heart disease from home helps cardiologists and technicians analyze data transmitted to computer platforms in a better way. The role of the patient in this new healthcare ecosystem is transformed into a co-creator of value more than ever before; the correct use of digital devices by patients is fundamental to provide continuous treatment and to guarantee patient autonomy.

Psychologically, it was very important for me to know that I am constantly monitored and that I can continue to be treated even from a distance. (Patient)

During the lockdown period, it was very important for me to know how to best use these technological devices. At first, I did not know how to relate to this new type of "remote treatment," then I understood the added value and also how much it saved us and her from going to the hospital. But at the beginning, I had to study this new device. (Husband of a patient)

During the pandemic, every patient can be a potential user of digital health devices, and it is necessary to consider both sides of the coin. On one side, patients, caregivers, families, and providers need to be aware of the use of these digital devices in order to optimize the prescribed therapy. The new adaptive interactions among actors also include more in-depth relationships between specialists; the work of the cardiologist is highly related to that of technicians, the family doctor, the psychologist, and so on. On the other side, the relationship between the patient and doctor changes radically because of the mediation of digital devices and the differences present in this new type of visit.

In this new digitally mediated ecosystem, it is also important to consider the engagement of private companies, such as Zucchetti SpA, which has made available to Monzino and to all Italian hospitals an advanced telemedicine software to monitor the parameters necessary to assess patient health outside hospital structures. The central role of the patient in this ecosystem also requires the development of new services based on subjectivity, culture, values, and preferences. The role of some health tech start-ups becomes important, as they permit the patient to virtually interact with clinicians, nutritionists, psychologists, and other members of the so-called care teams.

The pandemic significantly boosted new opportunities for my start-up to develop more humanized technological solutions to the healthcare system. In this situation, the continuous interaction with the cardiologists of Centro Cardiologico Monzino and their patients has represented a unique source of inspiration. (Health tech startup manager) 
Furthermore, many non-profit associations, at the meso level, have implemented new forms of caring; some of them are experiencing the so-called "volunteering via Internet," while some other non-profits and voluntary associations have expanded their mission in order to continue their core activities in a new way, which is useful in caring for chronic patients remotely. "We will have to introject the oxymoron that social distancing could be overcome through virtual social interaction via telephone or computer. Contact is relevant for the patient to decrease loneliness and fear of the disease" (President of a voluntary association).

Our analysis shows the importance of actor engagement, not only at the micro and meso levels as expected, but also at a macro level, such as the Ministry of Health and other institutional actors. The evolution of the Centro Cardiologico Monzino service ecosystem has also impacted, at the macro level, institutional actors, such as the Italian National Institute of Health, which foresaw and encouraged the use of telemedicine to allow hospitals located in the areas most affected by the pandemic, to use teleconsultation. After this notice, similar initiatives multiplied.

The Ministry of Health has set new guidelines for telemedicine in Italy. The document "Telemedicine - National Guidelines" (Rapporti ISS COVID-19 n. 12/2020) states:

Technological innovation can contribute to a reorganization of healthcare, in particular by supporting the shift of the focus of healthcare from the hospital to the territory, through innovative citizen-cantered care models and by facilitating access to services in the national territory. The modalities for the provision of health and socio-health services enabled by telemedicine are fundamental in this sense, contributing to ensure equity in access to care in remote territories, a support for the management of chronic conditions, a channel for access to high specialization, better continuity of care through multidisciplinary comparison and a fundamental aid for emergency-urgency services. (Rapporti ISS COVID-19 n. 12/2020)

Given the importance of telemedicine during this specific pandemic, institutional actors' coordination is necessary. To facilitate patient monitoring from home, the Ministry for Technological Innovation, together with the Ministry of Health and the WHO Higher Institute of Health, promoted a call to find telemedicine applications for patients who were at home either because they were affected by COVID-19 or other diseases, including chronic ones.

Specifically, in terms of heart diseases, the Digital Health Committee of the European Society of Cardiology (ESC) is working to move strategies in a digital direction; all the educational activities of ESC, its associations, and its working groups are becoming increasingly based on remote access and digital interactions (ESC 2020).

In this new digital service ecosystem approach, the engagement and the contributions of all actors at the micro, meso, and macro levels are important. They contribute in new-fangled ways to transformative value co-creation in order to give the right assistance to patients with chronic heart disease. 


\subsubsection{Resource Integration for Transformative Value}

The revolutionary switch to telemedicine and video consultation in order to prevent the spread of COVID-19 is not as straightforward as installing a new service; rather, it involves introducing and sustaining major changes to an already complex system. The use of telemedicine has to be considered an integration and not a simple substitution of traditional healthcare systems, and nowadays, it is a valid support tool on the path of treatment of heart disease. It must be adapted flexibly, with personalized logic, to the needs of the individual patient. The evolution of the traditional service ecosystem emphasizes the role of the different actors as value co-creators in a new transformative way due to the integration of different resources. For example, there is resource integration between nurses and caregivers. In the management of patients through telemedicine, nurses transmit their skills to caregivers and family members more effectively and have feedback about the patients' daily life issues for imagining possible solutions. The connection between technicians, cardiologists, and patients is also relevant. Thinking about the meso level, integrating resources leads to overcoming the boundaries and creating new networks. Dealing with resource integration, we have also to consider data integration: the digital environment is very complicated, and the integration of different and individual applications with core hospital systems is useful for communicating with other systems. Resource integration also involves team integration, concepts, skills, and technologies to create virtual infrastructures. At Centro Cardiologico Monzino, telemonitoring is carried out using an application that can be downloaded to a phone; every day, the patient records a series of fundamental data to understand the evolution of his or her clinical situation. The data are constantly analyzed at the control center, which in turn, contacts the patients at least twice a day to evaluate their clinical progress, indicating or integrating the existing therapy, organizing a series of targeted diagnostic tests and with constant "virtual human contact," which keeps the patient and their family from feeling abandoned and alone.

During this COVID-19 period, Centro Cardiologico Monzino activated a new service to remotely monitor the cardiorespiratory health of patients discharged from the hospital with COVID-19 pneumonia. It is a cutting-edge technology that allows patients to control their main vital parameters through special sensors built into the fabric of a t-shirt that the patient wears at home. The initiative is part of the Monzino model for Phase 2 of the COVID-19 emergency, which aims to strengthen surveillance and home care. The service provided by the t-shirt was originally developed for decompensation and clinical cardiology patients of Monzino.

The shirts are given to patients at discharge and configured to allow reading and transmission of data. A portable router is also given to the patient, which allows the patient to transmit the registration data even without using a telephone connection or a home data network. The kit also contains a series of practical instructions and a contact number to provide constant assistance and respond to any technical problems. The high-tech t-shirt records a twelve-lead electrocardiogram, the same that is performed in surgeries, and measures heart rate, arterial saturation, mechanics, and 
respiratory rate (including apneas). The device can be worn for any number of hours per day that the patient desires, though for a minimum of two hours, in which he must alternate, at set intervals, rest and standardized exercise, such as a walking around the home at a pace that anyone can sustain. In this way, it is possible to compare the parameters in the two situations and to get information if the patient performs the amount of physical movement in the house that is functional to healing.

The ability to monitor the patient remotely without the need to access the hospital unless worrying parameters have been observed; greater safety on the part of the subject, who feels monitored by advanced technology in the physically and psychologically delicate phase of post-discharge; greater self-monitoring by the patient, who is made aware of the need to gradually resume his daily life, at least within the home; and greater safety in the slightly earlier discharge of stable patients. (Clinician)

Telemedicine in this period is very important for patients with cardiac disease because, through different instruments, patients can stay in contact with their doctors, constantly monitor vital parameters through the use of wearable devices, and manage their emotional state through online support communities, mindfulness programs, and so on. Furthermore, in this way, the quality of care is enhanced and patient self-confidence is improved.

The adoption of remote patient monitoring (RPM) has exploded during the COVID-19 pandemic; these innovative and disruptive systems help care teams monitor, manage, and engage patients in the comfort of their homes, which contributes to reducing costs and mitigating risks. These systems continuously stratify patient risk via artificial intelligence (AI)-driven algorithms and alert and empower care teams with optimal windows of opportunity to intervene when needed. Automated visual/audio reminders and phone calls enable higher patient engagement and medication adherence. Integration with telehealth and virtual video conferencing and visits enables rapid patient health assessment, optimized for various chronic diseases.

Integration of different resources creates new resources in which the different actors act on different levels of engagement and co-create value to ensure the wellbeing of patients and society. One caregiver said:

It was not easy to manage his anxiety at the beginning and also the lack of trust in the health
system. "If I'm sick what happens?" was the most frequently asked question. The support
of a diverse community has been fundamental, and even in this period, I have had to learn
to be a caregiver in a different way. To no longer deal only with therapy, but also with the
use of devices and dealing with doctors and nurses by phone or via the Internet. (Caregiver)

In Phase 2 of the pandemic, the objective is to protect and monitor fragile patients and to do it is important the collaboration between family doctors, territorial health services, and service health centers in order to schedule proactive telephone surveillance interventions and control some vital parameters with simple monitoring tools to be delivered at home. 


\subsubsection{Newly Emerging Barriers and Tensions}

The new path defined by the evolution of the service ecosystem in a transformative direction is not without drawbacks. On one hand, there are some normative and technological barriers; on the other hand, there are tensions and resistance between the different actors in the process of resource integration.

The integration of digital health and health services could open the door to new, important, but complex, issues. The creation of a large amount of data generated by users is indeed useful for the health system, but at the same time, it generates questions regarding patient privacy, highlighting the need to establish privacy policies.

Protection of personal data, however, is a fundamental right of each individual. The high predictive analysis capacity allowed by the latest technologies represents a precious resource in emergency situations; the impacts, even in the long run, on the rights and freedoms of individuals cannot be underestimated. Where digital health is concerned, therefore, a reflection on the balance between health protection and privacy protection will be very important in order to build a post-emergency health system that is more democratic in accessibility and equally democratic in the defense of citizen individuality.

Today, even if there are limited high-quality and randomized data supporting telehealth, there is evidence suggesting the benefit to patients given by health systems. Telehealth interventions in cardiology to date have largely focused on ambulatory management of hypertension and heart failure. Analyses of randomized trials of telehealth in heart failure have shown improved clinical outcomes.

In general, during this period, digital reservations and prejudices have fallen, but methodological scruples and an orientation to critically rethink the ordinary methods of taking care of patients have remained in order to avoid transferring poorly suited organizational practices to digital.

Not all my colleagues appreciate telemedicine. Having fewer patients in the office for some doctors is implicitly related to the loss of power ... (Cardiologist)

For remote assistance, it is necessary to have safe technological tools that preserve the confidentiality of health data, but it is not enough for them to simply function and be used. It is essential to be able to co-construct diversified and customizable organizational and relational settings. In a very short time, virtual meetings were organized with the teams of each service to understand the needs and to build digital clinics capable of enhancing a personalized approach for the individual team. Technologies must not impose rigid and standardized organizational models and paths; on the contrary, they must help reinvent them.

The National Italian Health System today does not reimburse telemedicine services, and the adoption of new digital healthcare solutions by national systems must take this issue into consideration along with issues related to the integration with current information systems as well as the legal framework in data processing.

Another critical point is the lack of the presence of clinical and non-clinical staff and their appropriate training. This issue reflects the importance of the presence 
of trained staff because the greater the change of behavior needed (by physicians, nurses, providers, payers, and policy makers) to deliver new products or services, the greater the barriers to patients, despite the promises of value delivered by the new product or technology.

Summing up barriers and tensions could be summarized as follow:

- Normative and technological barriers

- Patient privacy

- Data protection

- Telemedicine reimbursement

- Clinical and non-clinical staff training.

\subsection{Transformative Value Co-creation Framework with New-Fangled Actors}

Considering the results of our analysis and our research setting, Fig. 4.1 represents Transformative Value Co-Creation in Monzino Service Ecosystem.

In the scheme, we have considered three different levels: micro, meso and macro with the patients at the center. The coordination process leveraged by technological devices integrates resources and co-creates transformative value at individual and collective levels.

The impact of technological devices requires and implies new relations and the creation of networks to better suit new practices required by this type of innovation (Geels and Schot 2007; Edvardsson et al. 2014).

The creation of new type of relationships and overcoming barriers and difficulties typical of creating new networks, between micro, meso and macro levels, is needed to develop this service ecosystem, but to act these new relations is important to create convergent logics among different actors (Öberg et al. 2016; Aarikka-Stenroos et al. 2017; Jaakkola et al. 2018). The co-existence of different layers and different actors at different involved in different ways, necessitates the engagement of actors in new practices (Edvardsson and Tronvoll 2013; Jaakkola et al. 2018).

Various actors, institutions and stakeholders such as clinicians, family doctors, nurses, caregivers, but also health tech start-ups, associations and so on at meso level, and Ministry of health, National health institutes and others at macro level, can impact transformative value co-creation and influence the institutionalization of new practices in society (Geels 2002).

At micro level patients, caregivers, family doctors, cardiologists and so on impact the success of the use of these new devices and influence also their institutionalization and usage in the society (Biemans 1991; Geels 2002; Aarikka-Stenroos et al. 2017). Intermediaries, such as technology providers and tech consultants, make the products available to users (Woodside and Biemans 2005). 


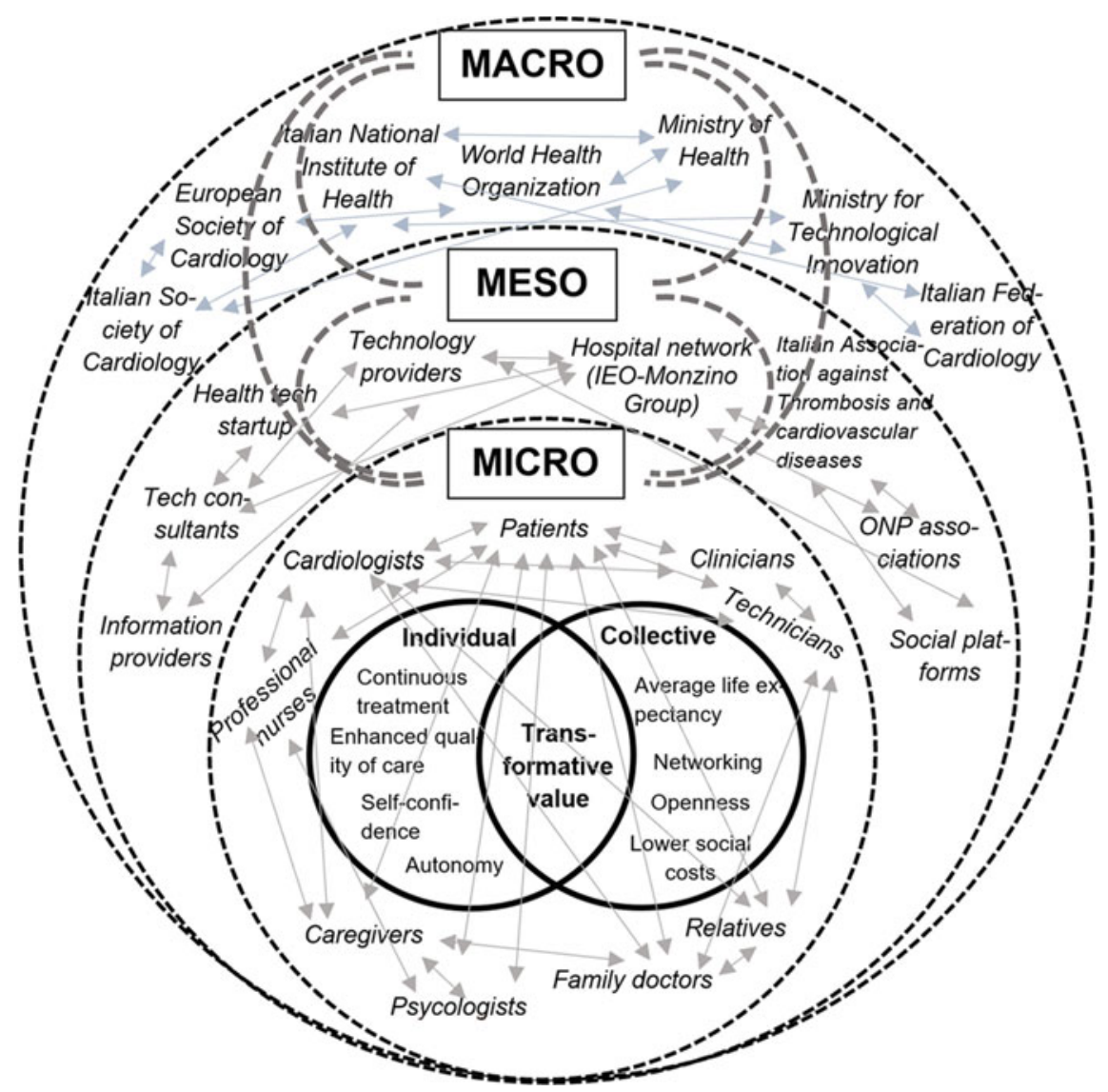

Fig. 4.1 Transformative value co-creation in Monzino service ecosystem

Public organizations and other institutions, at macro level, may support the diffusion by articulating positive visions of the use of the innovation in society (Troshani and Doolin 2007) also trying to limit barriers and tensions.

The case of Centro Cardiologico Monzino shows that the use of digital devices has potential to provide benefits for many stakeholders, but it also requires the presence of long term vision and sometimes a change driven from the macro level could force actions also at meso and micro levels in order to provide global benefits.

The digitally mediated healthcare service ecosystem nowadays emerges as a disruptive reality useful to provide new solutions and manage new links and actors' and resources' integration to co-create transformative value taking into account at the individual level, the continuity of treatment, the enhancement of quality of care, and patient autonomy and self-confidence. At the collective level, some variables to be considered in this framework are the increase in life expectancy, the variety and 
breadth of interaction in networks, the augmented openness towards innovation, and the decrease of social costs.

\subsection{Conclusions and Managerial Implications}

The use of digital technologies in healthcare systems brings about a new service ecosystem based on new adaptive interactions among actors that transforms the patient-provider relationship and on new social practices. In this new ecosystem, based on technology-mediated healthcare, new social practices grow and integration among actors' changes.

The use of telehealth has been growing in the past few years, though more slowly than expected. One major reason has been the lack of a reimbursement model for telemedicine that puts it on par with in-person visits. We may be seeing a tipping point that takes telehealth to the mainstream in one stroke, transforming the way we experience healthcare in the future. Most importantly, the public at large will become accustomed to telehealth visits as an acceptable way of obtaining healthcare.

A large body of scientific literature demonstrates the effectiveness of this system (Ganatra et al. 2020; De Rosa et al. 2020), which improves the management of these patients in terms of prognosis and quality of life while avoiding periodic visits to the hospital. Even if it is very difficult to not have a patient in front of the doctor, digital health and telemedicine is now a necessity, not only in Italy but worldwide.

Telemedicine and digital health technologies have proven to be very useful to allow cardiologists virtual visits and, when possible, electrocardiogram (ECG) reading and in general, continuous patient monitoring and immediate interventions. Furthermore, the use of digital technologies mitigates issues related to this emergency period, such as the fact that local doctors are exhausted from this situation and Italian laboratories have reduced non-urgent activities, especially in regions with a high number of COVID-19 patients.

The creation of these new "virtual clinics" is useful to the reduction of physical crowding in clinics and hospitals, and the use of digital technologies for patients with cardiovascular diseases has helped the tracking of patients and prevented them from a delay in treatments and unnecessary hospital consultations. Some studies suggest the importance of substituting in-person visits with telehealth visits (Ganatra et al. 2020) in order to reduce COVID-19 transmission among patients with cardiovascular disease and underline the importance of activating telehealth protocols as soon as possible.

Digital health proposes new ways to produce and provide services that differ from models based on the hospital structure. These are considered limiting, since the COVID-19 pandemic has highlighted the need for better use of healthcare resources with a view to achieving greater efficiency. Increasing the quality means having a huge amount of detailed data of all kinds of patients, pathologies, and/or lifestyles, 
thus being able to support medical figures in the delivery of personalized therapies without wasting resources and without incurring unnecessary expenses. Therefore, anyone could be a potential user of digital health devices, and this challenging context requires the development of people-centered services, which considers one's subjectivity, living environment, culture, values, constraints, and preferences.

In such emerging healthcare ecosystems, smart devices effectively connect the emotional, social, and physical needs of the actors (patients and their families, physicians, other service providers, etc.) to transform the patient into an active actor who integrates resources and co-creates value (Anderson et al. 2013; Danaher and Gallan 2016; Anderson et al. 2018).

This epidemic period represents a unique occasion to understand the real potential of digital transformation in the healthcare sector; never before has the speed of adopting a large-scale digital healthcare tool been so impactful. In this period in Italy, virtual experiences have multiplied, including the use of chatbots to detect COVID19 from the first symptoms and free specialized nursing tele-assistance services that provide support to patients, caregivers, and families and that create a new virtual network between partners.

Long after this pandemic has run its course, we will be left with enhanced structural changes in the way we work and communicate. These were happening already, but in a rather slow and piecemeal fashion. COVID-19 will accelerate this process and leave us transformed forever. Looking to the future, remote imaging assisted by artificial intelligence for image collection and interpretation may also reduce the need for patients to attend distant healthcare facilities - but we are a long way from this at the present time. Centro Cardiologico Monzino is working in this direction; simpler solutions than t-shirt are under study, these new solutions will be less invasive and will transmit data faster. Soon there will also be the possibility of measuring body temperature remotely, a particularly significant figure, as is known, for patients who have contracted COVID-19.

Many Italian hospitals, however, lack the necessary and technical resources; the use of digital health requires that services looking to use video consultations must ensure they are using appropriate software that properly aligns with clinical workflows. Platforms designed for video conferencing do not provide the appropriate workflow and may require software downloads that breach local information governance policies. Bandwidth, audio quality, and video quality must also be considered when implementing a system.

The future is digital-and likely more virtual than has traditionally been the case. Healthcare is no exception. Cardiology has already dipped a toe into these waters, and the COVID-19 pandemic will no doubt, continue to speed up the process of transformation. 


\section{Authors' Insight}

\section{Roberta Sebastiani, Alessia Anzivino}

Sometimes things happen and confront all of us with some hidden realities. Chronic illnesses, although diffused, have been somehow swept under the rug during the pandemic. In the last months, we have experienced new forms of vulnerability and have reflected on the different nuances that this term assumes, thinking about how to cope with it.

Nevertheless, surprisingly, it is around someone vulnerable, chronic patients, that old walls have begun to crumble, and a new conformation of the ecosystem has begun to define itself and strengthen. This implied the breaking of old patterns and the overcoming of consolidated boundaries.

Patients began to become more aware of their therapeutic paths, doctors approached different worlds, such as that of technologies, starting to acquire their logics and languages, ancillary figures such as nurses found themselves at the center of a process of retraining from which were left out for a long time.

The perfect storm, that we did not expect, confronts us with the need to finally become aware of the interrelationships between the health sector and other sectors.

Digital innovation-continuous care-patient-covid—attention-new network-new skills.

These are in our opinion the keywords that summarize what the present and the future in the management of the health sector will be.

Rather than creating a new service ecosystem, we think we should review the existing one and understand how everything that already exists could be re-read in the light of the disruptive changes brought by Covid.

The pandemic has led us to reflect in a new way on the organization of health services, on the need to put more attention to the prevention of similar events, but also and above all on the need to rethink the role of local medicine and focusing on the model proposed in this chapter on the connection between micro and meso levels.

A patient-centered health strategy must be accompanied by an equally decisive strategy centered on the community and the territory and it should be driven at macro level. The overcoming of barriers and the easing of tensions is possible only through new ways of integrations between actors and also to the reshape of some services. Patient associations or voluntary associations, for example, could reshape their mission in order to be as close as possible to patients and continue to offer their support in response to citizens' needs.

The problem is therefore mainly to look to the future with foresight, to confront different disciplines and their studies and results and to continue to support the creation and the development of new innovative project, such as the one by Philips and Pfizer called "Vicini di Salute".

Specifically based on the sharing of information and data between doctor and patient through a digital device, the Philips-Pfizer remote assistance program allows patients to be constantly connected with the doctor and receive alerts and reminders 
regarding adherence to therapy and follow-up, requests for monitoring vital signs, as well as motivational messages. The doctor is thus able to have the patient's condition under control and can intervene if necessary. And this is precisely the dual soul at the center of the project: on the one hand the continuous training of the staff of the healthcare facility, which can constantly monitor the patient, on the other the empowerment of the patient who, thanks to the use of innovative technologies and integrated, improves their care experience thanks to constant proximity to the doctor and greater involvement in their path of disease management.

Philips and Pfizer confirm their commitment to innovation in the service of health, combining their expertise respectively in terms of technological innovation in the health sector and know-how on pathologies, to activate the Vicini di Salute project for the second consecutive two years.

"The future is digital — and likely more virtual than has traditionally been the case", as we said at the end of chapter, but the future is also interconnection of different disciplines, the acquisition of new skills, the application of existing skills in a new way.

This renewal process hides many questions and challenges, despite the pandemic providing a boost that will spread its energy over time and space like a wave. We hope that with the contribution of all this energy should not be wasted but intelligently directed precisely where it is needed most.

\section{References}

Aarikka-Stenroos, L., Jaakkola, E., Harrison, D., \& Mäkitalo-Keinonen, T. (2017). How to manage innovation processes in extensive networks: A longitudinal study. Industrial Marketing Management, 67, 88-105.

Aceto, G., Persico, V., \& Pescapé, A. (2018). The role of Information and Communication Technologies in healthcare: Taxonomies, perspectives, and challenges. Journal of Network and Computer Applications, 107, 125-154.

Alexander, M. J., Jaakkola, E., \& Hollebeek, L. D. (2018). Zooming out: Actor engagement beyond the dyadic. Journal of Service Management., 29(3), 333-351.

Anderson, L., \& Ostrom, A. L. (2015). Transformative service research: Advancing our knowledge about service and well-being. Journal of Service Research, 18(3), 243-249.

Anderson, L., Ostrom, A. L., Corus, C., Fisk, R. P., Gallan, A. S., Giraldo, M., et al. (2013). Transformative service research: An agenda for the future. Journal of Business Research, 66(8), 1203-1210.

Anderson, S., Nasr, L., \& Rayburn, S. W. (2018). Transformative service research and service design: Synergistic effects in healthcare. The Service Industries Journal, 38(1-2), 99-113.

Biemans, W. G. (1991). User and third-party involvement in developing medical equipment innovations. Technovation, 11(3), 163-182.

Blocker, C. P., \& Barrios, A. (2015). The transformative value of a service experience. Journal of Service Research, 18(3), 265-283.

Carenity and Alira Health. (2020). www.prnewswire.com/news-releases/covid-19-and-chronic-ill nesses-will-chronic-patients-be-collateral-victims-of-the-pandemic-301040472.html?tc=eml_ cleartime. 
Caridà, A., Colurcio, M., \& Melia, M. (2014). Rethinking and improving the healthcare service through interactive web technologies. In E. Baglieri \& U. Karmarkar (Eds.), Managing consumer services: Factory or theater?. Cham (ZG), Switzerland: Springer International Publishing.

Chandler, J. D., \& Vargo, S. L. (2011). Contextualization and value-in-context: How context frames exchange. Marketing theory, 11(1), 35-49.

Danaher, T. S., \& Gallan, A. S. (2016). Service research in health care: Positively impacting lives. Journal of Service Research, 19(4), 433-437.

De Rosa, S., Spaccarotella, C., Basso, C., Calabrò, M. P., Curcio, A., Filardi, P. P., et al. (2020). Reduction of hospitalizations for myocardial infarction in Italy in the COVID-19 era. European Heart Journal, 41(22), 2083-2088.

Diener, E. (2006). Guidelines for national indicators of subjective well-being and ill-being. Journal of Happiness Studies, 7, 397-404.

Edvardsson, B., Kleinaltenkamp, M., Tronvoll, B., McHugh, P., \& Windahl, C. (2014). Institutional logics matter when coordinating resource integration. Marketing Theory, 14(3), 291-309.

Edvardsson, B., \& Tronvoll, B. (2013). A new conceptualization of service innovation grounded in S-D logic and service systems. International Journal of Quality \& Service Sciences, 5(1), 19-31. ESC Congress. (2020). The Digital Experience.

Evans, S. D., \& Prilleltensky, I. (2007). Youth and democracy: Participation for personal, relational, and collective well-being. Journal of community psychology, 35(6), 681-692.

Gabbrielli, F., Bertinato L., De Filippis G., Bonomini M., \& Cipolla M. (2020). Rapporti ISS COVID-19 n. 12/2020.

Ganatra, S., Hammond, S. P., \& Nohria, A. (2020, March 20). The novel coronavirus disease (COVID-19) threat for patients with cardiovascular disease and cancer. Journal of the American College of Cardiology, 2(2), 350-355.

Geels, F. W. (2002). Technological transitions as evolutionary reconfiguration processes: A multilevel perspective and a case-study. Research Policy, 31(8), 1257-1274.

Geels, F. W., \& Schot, J. (2007). Typology of sociotechnical transition pathways. Research Policy, 36(3), 399-417.

Horvath, A., Thomassen, B., \& Wydra, H. (Eds.). (2015). Breaking boundaries: Varieties of liminality. Oxford, UK: Berghahn.

Jaakkola, E., Aarikka-Stenroos, L., \& Ritala, P. (2018). Institutionalization process of service innovation: Overcoming competing institutional logics in service ecosystems. In P. P. Maglio, C. A. Kieliszewski, J. C. Spohrer, K. Lyons, Y. Sawatani, \& L. Patricio (Eds.), Handbook of service science (Vol. 2, pp. 497-516). Cham: Springer.

Lakkireddy, D. R., Chung, M. K., Deering, T. F., Gopinathannair, R., Albert, C. M., Epstein, L. M., et al. (2020). Guidance for rebooting electrophysiology through the COVID-19 pandemic from the Heart Rhythm Society and the American Heart Association Electrocardiography and Arrhythmias Committee of the Council on Clinical Cardiology. Heart Rhythm, 6(8), 1053-1066.

Lusch, R. F., \& Vargo, S. L. (2014). The service-dominant logic of marketing: Dialog, debate, and directions. London: Routledge.

Öberg, C., Shih, T. T. Y., \& Chou, H. H. (2016). Network strategies and effects in an interactive context. Industrial Marketing Management, 52, 117-127.

Osei-Frimpong, K., Wilson, A., \& Lemke, F. (2018). Patient co-creation activities in healthcare service delivery at the micro level: The influence of online access to healthcare information. Technological Forecasting and Social Change, 126, 14-27.

Saborowski, M., \& Kollak, I. (2015). "How do you care for technology?"-Care professionals' experiences with assistive technology in care of the elderly. Technological Forecasting and Social Change, 93, 133-140.

Troshani, I., \& Doolin, B. (2007). Innovation diffusion: A stakeholder and social network view. European Journal of Innovation Management, 10(2), 176-200.

Vargo, S. L., \& Lusch, R. F. (2011). It's all B2B... and beyond: Toward a systems perspective of the market. Industrial Marketing Management, 40(2), 181-187. 
Vargo, S. L., \& Lusch, R. F. (2016). Institutions and axioms: An extension and update of servicedominant logic. Journal of the Academy of Marketing Science, 44(1), 5-23.

Vargo, S. L., Wieland, H., \& Akaka, M. A. (2015). Innovation through institutionalization: A service ecosystems perspective. Industrial Marketing Management, 44, 63-72.

Webster, P. (2020). Virtual health care in the era of COVID-19. Lancet, 395(10231), 1180-1181.

Woodside, A. G., \& Biemans, W. G. (2005). Modeling innovation, manufacturing, diffusion and adoption/rejection processes. Journal of Business \& Industrial Marketing, 20(7), 380-393.

World Health Organization. (2020). www.who.int/health-topics/cardiovascular-diseases. Accessed 21 May 2020.

www.infectioncontroltoday.com/view/fight-covid-19-telemedicine.

www.escardio.org/Education/Digital-Health-and-Cardiology/Virtual-Journal/editorial-board-dig ital-health-portal-and-the-journal-of-esc-digital-health.

Roberta Sebastiani is Full Professor of Management at Catholic University of the Sacred Heart. Co-Director of Centrimark - Center for Marketing Research—and Director of the Master Program in Marketing Management at the same University. The research and teaching interests include sustainable strategy and business ethics, transformative service research and service innovation.

\begin{abstract}
Alessia Anzivino is Post Doc at Catholic University of the Sacred Heart, university where she received her Ph.D. in Management. She is researcher at Centrimark (Marketing Research Center) and Professor of Marketing. Her main topics of research concern value creation in the management of strategies, business dynamics and sustainability.
\end{abstract}

Open Access This chapter is licensed under the terms of the Creative Commons AttributionNonCommercial-NoDerivatives 4.0 International License (http://creativecommons.org/licenses/bync-nd/4.0/), which permits any noncommercial use, sharing, distribution and reproduction in any medium or format, as long as you give appropriate credit to the original author(s) and the source, provide a link to the Creative Commons licence and indicate if you modified the licensed material. You do not have permission under this licence to share adapted material derived from this chapter or parts of it.

The images or other third party material in this chapter are included in the chapter's Creative Commons licence, unless indicated otherwise in a credit line to the material. If material is not included in the chapter's Creative Commons licence and your intended use is not permitted by statutory regulation or exceeds the permitted use, you will need to obtain permission directly from the copyright holder.

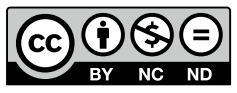

